\title{
Long-Term, Gridded Standardized Precipitation Index for Hawai'i
}

\author{
Matthew P. Lucas ${ }^{1}$, Clay Trauernicht ${ }^{2, *}$, Abby G. Frazier 1,3,*(D) and Tomoaki Miura ${ }^{2}$ (D) \\ 1 Department of Geography and Environment, University of Hawai'i at Mānoa, Honolulu, HI 96822, USA; \\ mplucas@hawaii.edu \\ 2 Department of Natural Resources and Environmental Management, University of Hawai'i at Mānoa, \\ Honolulu, HI 96822, USA; tomoakim@hawaii.edu \\ 3 East-West Center, Honolulu, HI 96848, USA \\ * Correspondence: trauerni@hawaii.edu (C.T.); abbyf@hawaii.edu (A.G.F.); \\ Tel.: +1-808-956-6875 (C.T.); +1-808-944-7729 (A.G.F.)
}

Received: 17 September 2020; Accepted: 18 November 2020; Published: 26 November 2020

\begin{abstract}
Spatially explicit, wall-to-wall rainfall data provide foundational climatic information but alone are inadequate for characterizing meteorological, hydrological, agricultural, or ecological drought. The Standardized Precipitation Index (SPI) is one of the most widely used indicators of drought and defines localized conditions of both drought and excess rainfall based on period-specific (e.g., 1-month, 6-month, 12-month) accumulated precipitation relative to multi-year averages. A 93-year (1920-2012), high-resolution $(250 \mathrm{~m})$ gridded dataset of monthly rainfall available for the State of Hawai'i was used to derive gridded, monthly SPI values for 1-, 3-, 6-, 9-, 12-, 24-, 36-, 48-, and 60-month intervals. Gridded SPI data were validated against independent, station-based calculations of SPI provided by the National Weather Service. The gridded SPI product was also compared with the U.S. Drought Monitor during the overlapping period. This SPI product provides several advantages over currently available drought indices for Hawai'i in that it has statewide coverage over a long historical period at high spatial resolution to capture fine-scale climatic gradients and monitor changes in local drought severity.
\end{abstract}

Dataset: https://doi.org/10.4211/hs.822553ead1d04869b5b3e1e3a3817ec6.

Dataset License: This dataset is licensed under a CC0 1.0 Universal (CC0 1.0) Public Domain Dedication license.

Keywords: Standardized Precipitation Index; drought; Hawai'i; gridded data; climate; rainfall

\section{Summary}

Hawai'i is characterized by extreme variability in rainfall in both space and time [1,2] due primarily to trade winds, land heating, and the archipelago's complex topography. Rainfall ranges in Hawai'i are greater than those found on some continents, with extreme spatial variation found between wet windward areas (up to 10,000 $\mathrm{mm}$ per year) and dry leeward locations (less than $300 \mathrm{~mm}$ per year) [1]. A long history of plantation agriculture has led to the development of a dense network of rain gauges to attempt to capture these fine-scale variations. Recent efforts to compile and spatially interpolate historical weather station data have resulted in the development of long-term (1920-2012) high-resolution gridded monthly rainfall data for the State of Hawai'i [3]. These new products and analyses provide an unprecedented opportunity to understand the effects and impacts of rainfall variability in Hawai'i over time and space. While spatial trends in seasonal rainfall have been 
examined [2], these high-resolution datasets have yet to be utilized to study drought in the islands. Drought is a significant feature of the climate in Hawai' $i$, and identifying and characterizing drought and drought response is critical due to the acute, severe impacts such as increasing the risk of fire, crop yield losses, reduced groundwater recharge, mortality of native species, and negative impacts on traditional cultural practices [4-6].

At present, there are only a few drought products available for Hawai'i with limited spatial and temporal coverage [7], as Hawai'i is not included in many of the indices produced for the conterminous U.S. (e.g., the Crop Moisture Index [8] and the Palmer Drought Severity Index (PDSI) [9]). The Keetch-Byram Drought Index [10] is calculated daily by the National Weather Service for fire risk monitoring and is available from 1985 to present, but only for one location in the state (Honolulu International Airport). This limits its utility for real-time fire risk assessments in other locations in the state. The Standardized Precipitation Index (SPI) [11] is calculated at a limited number of stations by the National Weather Service Honolulu Office (NWS; https://www.weather.gov/hfo/fullspi), however, only the most recent 12 months are available online to the public. The U.S. Drought Monitor [12] (USDM; https://droughtmonitor.unl.edu/), in contrast, provides statewide spatial patterns and categorical drought statistics that are updated weekly. The USDM has been operational since 2000 and is the most widely used drought resource in Hawai'i. The USDM incorporates rainfall data from multiple weather stations and on-the-ground drought impact reporting through expert analysis. However, the spatial delineations can be arbitrary and coarse, and the categorical values and short record length limit the value for numerical analysis and characterizing changes over time. Natural resource managers, farmers, and utilities need high-spatial and -temporal resolution products for monitoring drought conditions and making both short-term and long-term decisions.

In response to these needs and the shortcomings of available products, the existing gridded monthly rainfall dataset [3] was used to develop a long-term (1920-2012) dataset of the high-resolution (250 m) gridded Standardized Precipitation Index (SPI) [11] for the State of Hawai'i. The SPI is one of the most widely used drought indices since it is based solely on precipitation and, unlike the Palmer Severity Drought Index (PDSI), SPI allows easy comparison of standardized precipitation across regions with different climates [11,13]. Additionally, SPI allows the user to calculate levels of drought (and excess rainfall) for different time intervals (e.g., one-month, three-month, six-month) which can reflect meteorological, agricultural, and hydrological drought impacts [11,13]. Since SPI compares current precipitation with its local, multi-year average (see Methods), SPI allows wet and dry climates to be represented on a common scale to enable comparisons. SPI does not consider other important variables relating to drought, such as soil moisture or potential evapotranspiration, that are integrated into other indices such as PDSI [9] or the Standardized Precipitation and Evapotranspiration Index (SPEI) [14]. However, at present, only gridded monthly rainfall data have been published for Hawai'i [3], preventing the calculation of indices like PDSI and SPEI.

\section{Data Description and Methods}

This dataset contains the gridded monthly Standardized Precipitation Index (SPI) at 10 timescales: 1-, 3-, 6-, 9-, 12-, 18-, 24-, 36-, 48-, and 60-month intervals from 1920 to 2012 at $250 \mathrm{~m}$ resolution for seven of the eight main Hawaiian Islands $\left(18.849^{\circ} \mathrm{N}, 154.668^{\circ} \mathrm{W}\right.$ to $22.269^{\circ} \mathrm{N}, 159.816^{\circ} \mathrm{W}$; the island of $\mathrm{Ni}$ ihau is excluded due to lack of data). The gridded data use the World Geographic Coordinate System 1984 (WGS84) and are stored as individual GeoTIFF files for each month-year, organized by SPI interval, as indicated by the GeoTIFF file name. Thus, for example, the file "spi3_1999_11.tif" would contain the gridded 3-month SPI values calculated for the month of November in the year 1999. Currently, the data are available from 1920 to 2012, but the datasets will be updated as new gridded monthly rainfall data become available. Data are available to download at https://www.hydroshare.org [15]. 


\subsection{Calculating Gridded SPI}

SPI is a normalized drought index that converts monthly rainfall totals into the number of standard deviations (z-score) by which the observed, cumulative rainfall diverges from the long-term mean. The conversion of raw rainfall to a z-score is performed by fitting a designated probability distribution function to the observed precipitation data for a site. In doing so, anomalous rainfall quantities take the form of positive and negative SPI z-scores. Additionally, because distribution fitting is based on long-term ( $>30$ years) precipitation data at that location, the SPI score is relative, making comparisons across different climates possible.

The creation of a statewide Hawai'i SPI dataset relied on a 93-year (1920-2012) high-resolution (250 m) spatially interpolated monthly gridded rainfall dataset [3]. This dataset is recognized as the highest-quality precipitation data available $[2,6,16,17]$ for the main Hawaiian Islands. After performing extensive quality control on the monthly rainfall station data (including homogeneity testing of over 1100 stations [1,3]) and a geostatistical method comparison, ordinary kriging was used to generate a time series of gridded monthly rainfall from January 1920 to December 2012 at $250 \mathrm{~m}$ resolution [3]. This dataset was then used to calculate the monthly SPI for 10 timescales (1-, 3-, 6-, 9-, 12-, 18-, 24-, 36-, 48-, and 60-month) at each grid cell. A 3-month SPI in May 2001, for example, represents the March-April-May (MAM) total rainfall in 2001 compared to the MAM rainfall in the entire time series. The resolution of the gridded rainfall dataset provides a more precise representation of drought (and pluvial) events compared to the other available drought products.

To create the gridded SPI dataset from the gridded monthly rainfall data, the "SPI" function from the "SPEI" package [18] in R [19] was used to calculate the SPI at every grid cell $(n=287,982)$ in the monthly rainfall dataset [3]. The "SPI" function fits a gamma distribution to each pixel time series over the entire 93-year period (1920-2012) using unbiased probability weighted moments from which monthly SPI values were calculated. The use of the entire 93-year time series rather than a more limited reference period (e.g., 30 years) ensures a robust characterization of local rainfall and drought climatology [20]. This process was repeated for each of the 10 SPI timescales.

\subsection{Validation}

Gridded results were validated against an independent station-based time series of SPI provided by the NWS Honolulu Office (K. Kodama, unpublished data) for the 1-, 3-, 6-, 12-, 18-, and 24-month SPI. Monthly values from the novel gridded product for each SPI timescale were extracted at the location and aligned with the full time series (all spanning 3 or more decades) available for each set of station-based calculations ( $N=186,448$ across 42 stations). The two datasets were evaluated independently for each county (Kaua'i, Honolulu ( $\left.\mathrm{O}^{\prime} \mathrm{ahu}\right)$, Maui, and Hawai'i) as well as statewide using $\mathrm{R}^{2}$, root mean squared error (RMSE), mean absolute error (MAE), and mean biased error (MBE) statistics [21].

As another objective validation of the gridded SPI dataset, a comparison of the gridded SPI results with the USDM was performed. It is expected that differences will be found between the USDM and SPI products, as their methodologies and input datasets differ. We also acknowledge that the USDM data cannot be regarded as a metric of ground truth, however, they have been widely used in Hawai'i as the main source of drought information, and have been used to validate drought indices in a variety of other studies [12,22-24]. The SPI values were converted to the USDM categories (D0-D4) using the percentiles approach used by the USDM shown in Table $1[12,22,23]$. For each month and each SPI timescale, the percent of the land area with SPI values within each USDM drought category range (Table 1) was calculated. The weekly USDM percent area statistics were averaged to monthly for comparison with the monthly SPI values. $\mathrm{R}^{2}$, RMSE, MAE, and MBE statistics [21] were then calculated between the percent area values in each USDM category and each SPI timescale. Values were compared for each county as well as statewide. 
Table 1. The SPI values are converted using the USDM classifications ([22]).

\begin{tabular}{ccc}
\hline USDM Category & Percentile Chance & SPI Range \\
\hline D0: Abnormally dry & From $>20$ to 30 & From -0.5 to -0.7 \\
D1: Moderate drought & From $>10$ to 20 & From -0.8 to -1.2 \\
D2: Severe drought & From $>5$ to 10 & From -1.3 to -1.5 \\
D3: Extreme drought & From $>2$ to 5 & From -1.6 to -1.9 \\
D4: Exceptional drought & $\leq 2$ & $\leq-2.0$ \\
\hline
\end{tabular}

\section{Validation Results}

Validation analysis with the NWS station data indicated that the gridded data performed well statewide across all available SPI timesteps with $\mathrm{R}^{2}$ values ranging from 0.8 to 0.85 , RMSE values from 0.39 to 0.48 , and MBE ranging from -0.02 to 0.07 for the 1-, 3-, 6-, 12-, 18-, and 24-month SPI (Figure 1). Most of the average MBE values were positive, indicating that the gridded data tend to over-predict the SPI compared to the station data. Per county, all SPI validations had similar results (median $\mathrm{R}^{2}=0.84$, range $=0.75$ to 0.90 ; Table 2 ). Results across different SPI timescales were similar, with SPI-3 and SPI-6 having the best overall performance, and SPI-24 performing the worst (highest errors, lowest $\mathrm{R}^{2}$; Table 2).

(a)

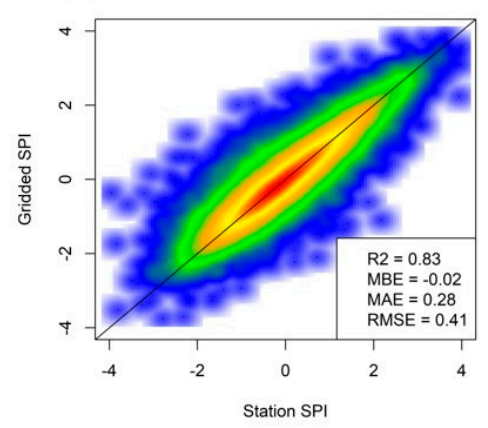

(d)

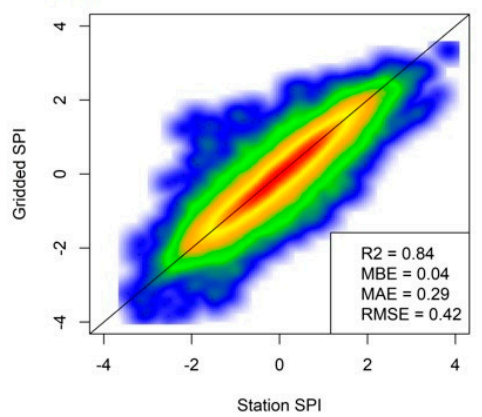

(b) HI Statewide: SPI 3

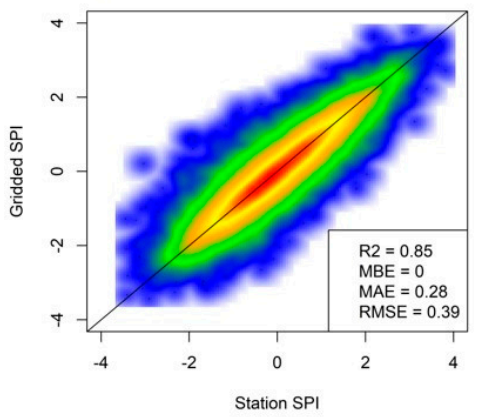

(e)

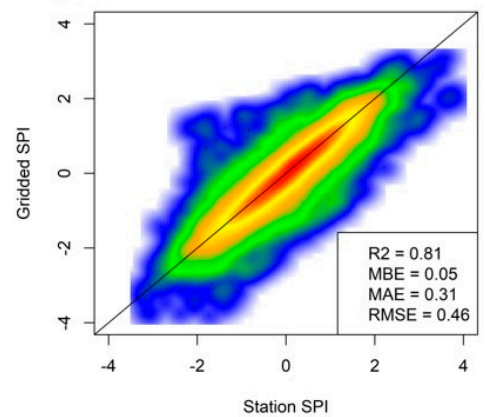

(c) HI Statewide: SPI 6

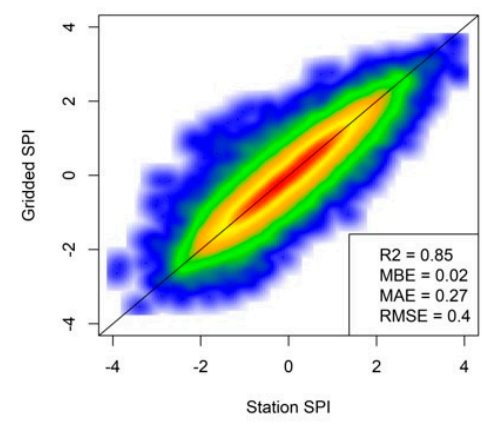

(f) HI Statewide: SPI 24

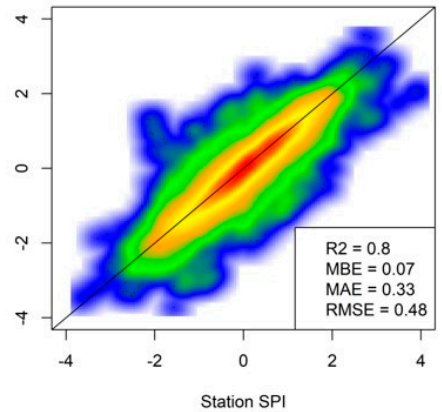

Figure 1. Density scatterplots between the gridded and station-based SPI for: (a) 1-month SPI; (b) 3-month SPI; (c) 6-month SPI; (d) 12-month SPI; (e) 18-month SPI; and (f) 24-month SPI. Validation statistics shown in lower right corner: Pearson $\mathrm{R}^{2}$ correlation coefficient, mean bias error (MBE), mean absolute error (MAE), and root mean square error (RMSE). 
Table 2. Validation results ( $\mathrm{R}^{2}$ and RMSE) of the gridded SPI product against station-based calculations by the National Weather Service per SPI timescale per county.

\begin{tabular}{cccc}
\hline SPI Timescale & County & $\mathbf{R}^{\mathbf{2}}$ & RMSE \\
\hline \multirow{2}{*}{ 1-month } & Hawai'i & 0.80 & 0.45 \\
& Kaua'i & 0.88 & 0.34 \\
& Maui & 0.83 & 0.42 \\
\multirow{3}{*}{ 3-month } & O'ahu $^{\prime}$ & 0.84 & 0.40 \\
& Hawai'i & 0.82 & 0.44 \\
& Kaua'i & 0.90 & 0.32 \\
& Maui & 0.85 & 0.39 \\
6-month & O'ahu & 0.85 & 0.38 \\
& Hawai'i & 0.82 & 0.45 \\
& Kaua'i & 0.90 & 0.33 \\
& Maui & 0.85 & 0.40 \\
12-month & O'ahu & 0.86 & 0.38 \\
& Hawai'i & 0.80 & 0.48 \\
& Kaua'i & 0.88 & 0.36 \\
& Maui & 0.83 & 0.42 \\
18-month & O'ahu & 0.85 & 0.40 \\
& Hawai'i & 0.78 & 0.52 \\
& Kaua'i & 0.87 & 0.38 \\
& Maui & 0.81 & 0.45 \\
& O'ahu & 0.82 & 0.44 \\
24-month & Hawai'i & 0.76 & 0.54 \\
& Kaua'i & 0.86 & 0.39 \\
& Maui & 0.80 & 0.48 \\
& O'ahu & 0.81 & 0.46 \\
\hline
\end{tabular}

Comparing the gridded SPI with the USDM for the overlapping period (2000-2012) indicates that the SPI classifies a larger percent of the land area in more severe classes of drought, as seen in Figure 2 and by the positive MBE values for D3 and D4 (Figure 3d). The bias errors for the statewide data show an underestimation of the percent of area in the D0 category in the SPI compared to the USDM, and an overestimation of areas in the D4 category, especially for SPI-18 and SPI-24 (Figure 3d). The SPI-3 grids had the lowest RMSE and MAE when compared with the USDM percent area (Figure 3), while SPI-6 had the highest $\mathrm{R}^{2}$. SPI-3 has been used in other studies to compare with the USDM, along with SPI-6, e.g., $[22,23]$. The individual county results are similar, in that SPI-3 and SPI-6 overall performed better than SPI-18 and SPI-24 (not shown). Since the USDM conditions tend to show shorter-term drought conditions, not longer-term (24-month) conditions, it is expected that SPI-3 and SPI-6 would perform better than SPI-24. One of the largest differences seen in the county-level results is that the USDM over this period (2000-2019) has never categorized any portions of Kaua'i or Honolulu counties as having any D4 conditions, while the SPI maps often show D4 conditions (not shown). This again speaks to the drier tendencies in the SPI dataset compared to the USDM.

When the spatial patterns for a sample period are compared (September 2010 which experienced D4 drought conditions, Figure 4), there is a greater land area shown in the D4 drought category in the SPI map compared to the USDM map. From this comparison, it is also clear that the USDM drought areas are shown as smooth polygons, while the higher-resolution SPI map can display greater detailed drought conditions. These maps also show some conflicting results, such as on the island of Maui where the USDM indicates D3 conditions in the western side and D0 on the eastern side, while the SPI-3 map shows D3 conditions on the eastern side and D0 conditions on the western side. 

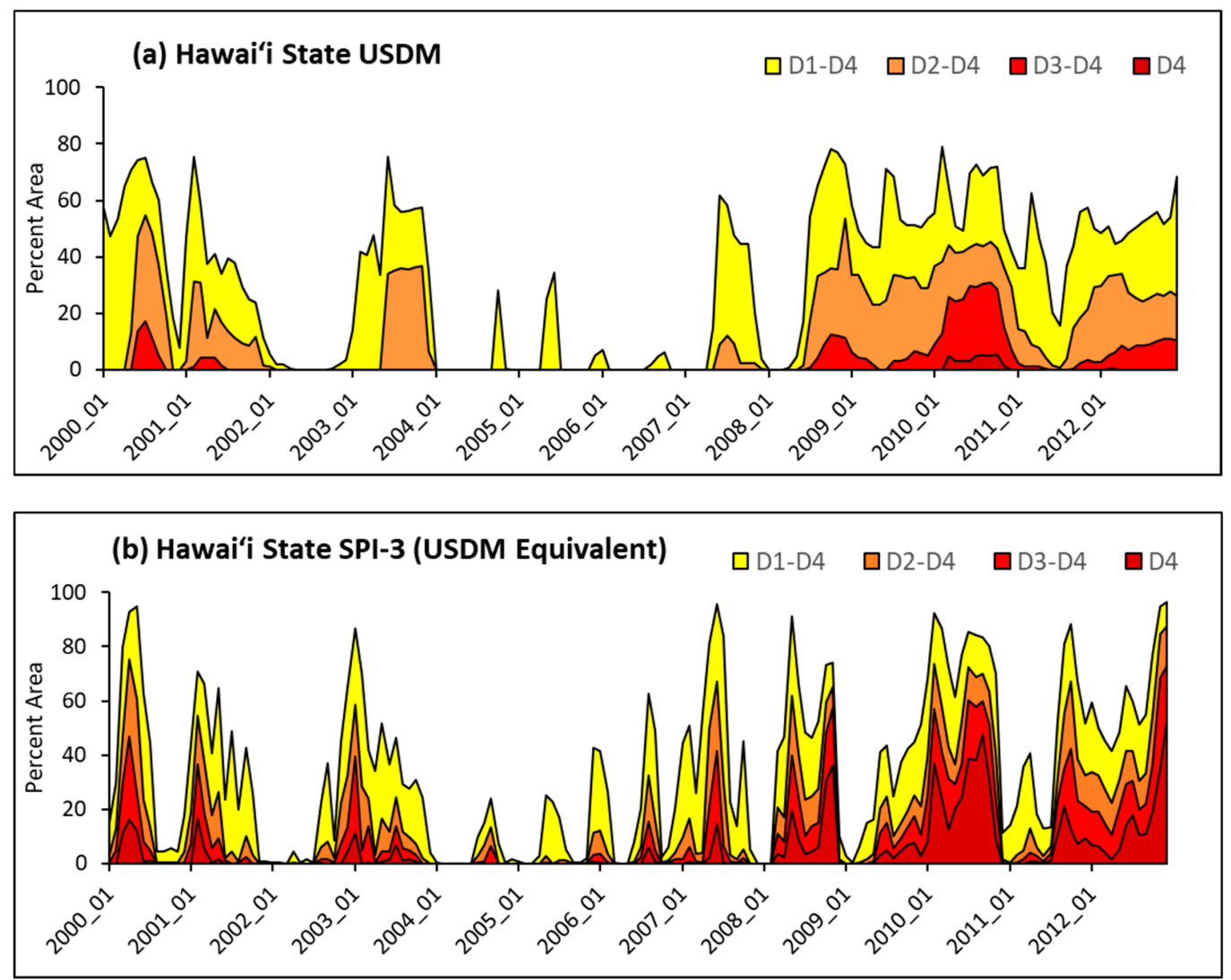

Figure 2. Percent area drought time series (2000-2012) for the State of Hawai'i for: (a) monthly aggregated U.S. Drought Monitor; and (b) gridded SPI-3 converted to USDM categories.
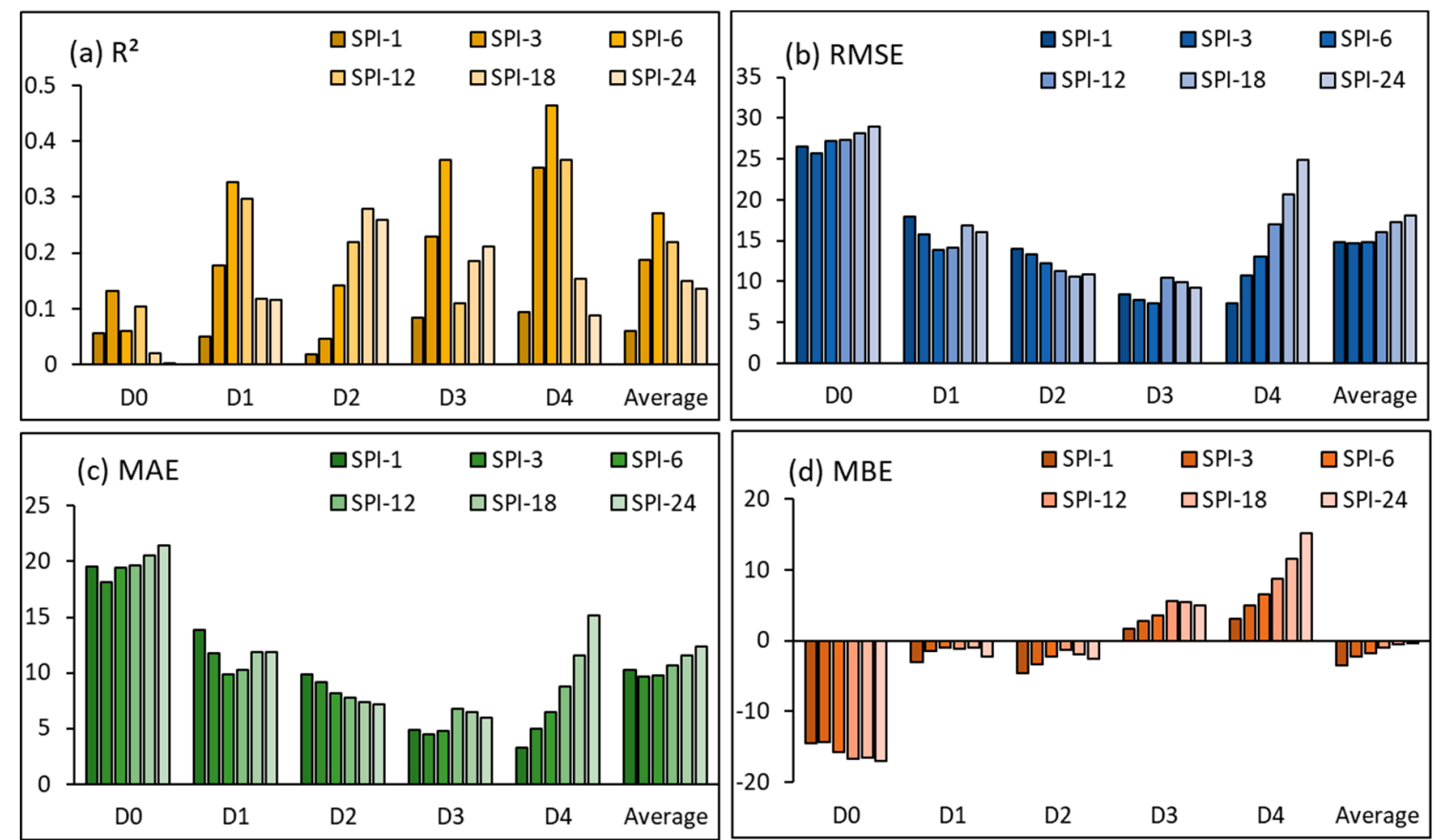

Figure 3. Validation statistics comparing USDM and SPI percent area for each drought category (D0-D4) for six SPI periods (1-, 3-, 6-, 12-, 18-, and 24- month SPI) for the State of Hawai'i (2000-2012). (a) Pearson $\mathrm{R}^{2}$ correlation coefficient; (b) root mean square error (RMSE); (c) mean absolute error (MAE); and (d) mean bias error (MBE). 


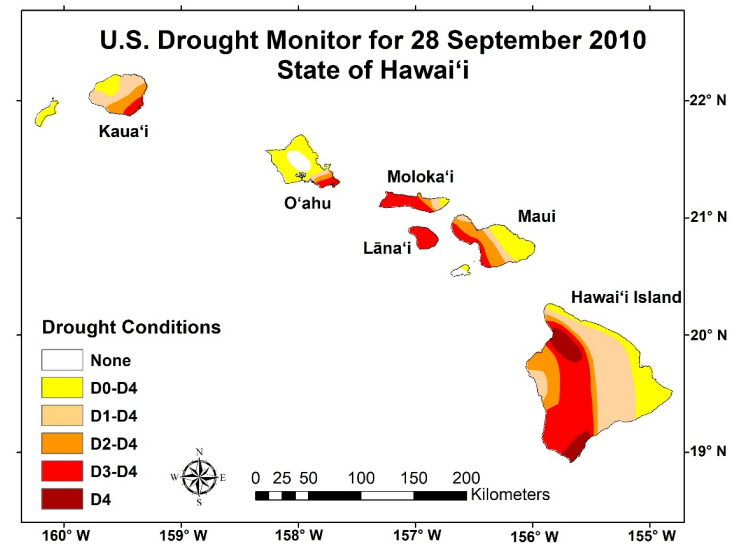

(a)

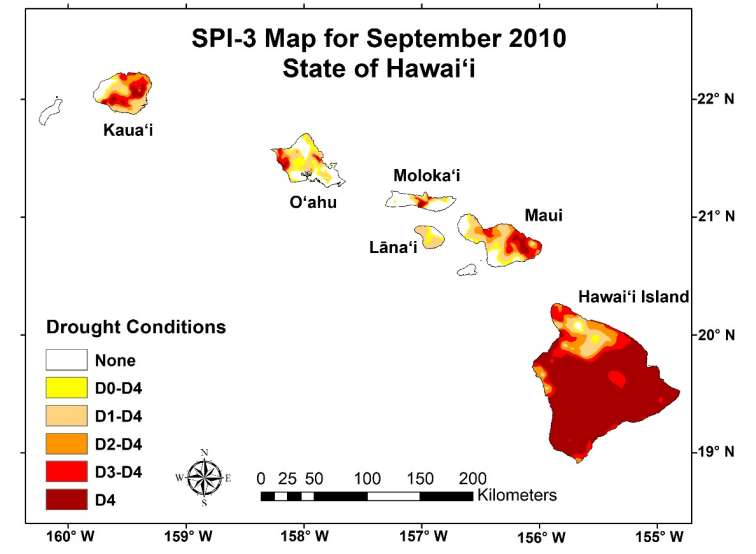

(b)

Figure 4. (a) USDM map from 28 September 2010, [12] https://droughtmonitor.unl.edu/; (b) September 2010 3-month SPI map with colors shown on the USDM scale.

\section{Data Use and Application}

This new dataset fills an important gap in the State of Hawai'i, providing long-term high-spatial resolution data to characterize drought regimes and changes through time. The complex spatial patterns and steep gradients in climate found here require higher-spatial resolution products to quantify changes at finer scales. Furthermore, given that Hawai' $i$ is not included in many national products and the USDM product only became available in the year 2000, this new gridded SPI product will allow analyses of long-term changes and how these trends can inform responses such as water infrastructure improvements, fire risk reduction, and long-term forest management planning. One major limitation of this gridded SPI dataset is that it ends in the year 2012, which happened to be during a very strong drought (Figure 2). Until now, new input rainfall grids have not been available past 2012. However, work is underway to update the monthly rainfall dataset to real time. Once these new products are available, the gridded SPI dataset will be updated past 2012 and produced in real time, accessible at the same location [15]. A real-time SPI product will result in additional tools available for drought monitoring and analysis in Hawai'i.

Author Contributions: Conceptualization, M.P.L., C.T., A.G.F. and T.M.; methodology, M.P.L. and C.T.; software, M.P.L.; validation, M.P.L., C.T., and A.G.F.; writing-original draft preparation, M.P.L., C.T., and A.G.F.; writing-review and editing, M.P.L., C.T., A.G.F. and T.M.; visualization, A.G.F.; funding acquisition, T.M. and A.G.F. All authors have read and agreed to the published version of the manuscript.

Funding: This research was partially supported by a USDA Hatch research grant $(1143 \mathrm{H})$, and the Pacific Islands Climate Adaptation Science Center Award Number G19PG00021.

Acknowledgments: The authors would like to acknowledge the Joint Fire Science Program for continuing support to $\mathrm{CT}$ and the USDA McEntire-Stennis and Hatch programs for funding.

Conflicts of Interest: The authors declare no conflict of interest.

\section{References}

1. Giambelluca, T.W.; Chen, Q.; Frazier, A.G.; Price, J.P.; Chen, Y.-L.; Chu, P.-S.; Eischeid, J.K.; Delparte, D.M. Online rainfall atlas of hawai'i. Bull. Am. Meteorol. Soc. 2013, 94, 313-316. [CrossRef]

2. Frazier, A.G.; Giambelluca, T.W. Spatial trend analysis of Hawaiian rainfall from 1920 to 2012. Int. J. Climatol. 2017, 37, 2522-2531. [CrossRef]

3. Frazier, A.G.; Giambelluca, T.W.; Diaz, H.F.; Needham, H.L. Comparison of geostatistical approaches to spatially interpolate month-year rainfall for the Hawaiian Islands. Int. J. Climatol. 2016, 36, 1459-1470. [CrossRef]

4. Giambelluca, T.W.; Nullet, M.A.; Ridgley, M.A.; Eyre, P.R.; Moncur, J.E.T.; Price, S. Drought in Hawai'i; Report R88; University of Hawai'i at Mānoa and U.S. Geological Survey: Honolulu, HI, USA, 1991; 232p. 
5. Frazier, A.G.; Deenik, J.L.; Fujii, N.D.; Funderburk, G.R.; Giambelluca, T.W.; Giardina, C.P.; Helweg, D.A.; Keener, V.W.; Mair, A.; Marra, J.J.; et al. Managing effects of drought in Hawai'i and U.S.-affiliated pacific islands. In Effects of Drought on Forests and Rangelands in the United States: Translating Science into Management Responses; Vose, J.M., Peterson, D.L., Luce, C.H., Patel-Weynand, T., Eds.; Gen. Tech. Rep. WO-98; Department of Agriculture Forest Service, Washington Office: Washington, DC, USA, 2019; Chapter 5, pp. 95-121.

6. Trauernicht, C. Vegetation-Rainfall interactions reveal how climate variability and climate change alter spatial patterns of wildland fire probability on Big Island, Hawaii. Sci. Total Environ. 2019, 650, 459-469. [CrossRef] [PubMed]

7. Commission on Water Resources Management (CWRM). Hawaii Drought Plan. Report Prepared for State of Hawaii Department of Land and Natural Resources; One World One Water, LLC: Honolulu, HI, USA, 2017; 131p.

8. Palmer, W.C. Keeping track of crop moisture conditions, nationwide: The new crop moisture index. Weatherwise 1968, 21, 156-161. [CrossRef]

9. Palmer, W.C. Meteorological Drought; Res. Pap. No. 45; U.S. Weather Bureau: Washington, DC, USA, $1965 ;$ p. 58.

10. Keetch, J.J.; Byram, G.M. A Drought Index for Forest Fire Control; US Department of Agriculture, Forest Service, Southeastern Forest Experiment Station: Asheville, NC, USA, 1968. [CrossRef]

11. McKee, T.B.; Doesken, N.J.; Kleist, J. The relationship of drought frequency and duration to time scales. In Proceedings of the Paper presented at the Eighth Conference on Applied Climatology, Anaheim, CA, USA, 17-22 January 1993; pp. 17-22.

12. Svoboda, M.; Lecomte, D.; Hayes, M.; Heim, R.; Gleason, K.; Angel, J.; Rippey, B.; Tinker, R.; Palecki, M.; Stooksbury, D.; et al. The drought monitor. Bull. Am. Meteorol. Soc. 2002, 83, 1181-1190. [CrossRef]

13. Hayes, M.; Svoboda, M.; Wall, N.; Widhalm, M. The Lincoln declaration on drought indices: Universal meteorological drought index recommended. Bull. Am. Meteorol. Soc. 2011, 92, 485-488. [CrossRef]

14. Vicente-Serrano, S.M.; Beguería, S.; López-Moreno, J.I. A multiscalar drought index sensitive to global warming: The standardized precipitation evapotranspiration index. J. Clim. 2010, 23, 1696-1718. [CrossRef]

15. Lucas, M.; Trauernicht, C.; Frazier, A.; Miura, T. Long-Term, Gridded Standardized Precipitation Index for Hawai'i: CUAHSI HydroShare. Available online: https:/www.hydroshare.org/resource/ 822553ead1d04869b5b3e1e3a3817ec6/ (accessed on 16 September 2017).

16. Frauendorf, T.C.; MacKenzie, R.A.; Tingley, R.W.; Frazier, A.G.; Riney, M.H.; El-Sabaawi, R.W. Evaluating ecosystem effects of climate change on tropical island streams using high spatial and temporal resolution sampling regimes. Glob. Chang. Biol. 2019, 25, 1344-1357. [CrossRef] [PubMed]

17. Newman, A.J.; Clark, M.P.; Longman, R.J.; Gilleland, E.; Giambelluca, T.W.; Arnold, J.R. Use of daily station observations to produce high-resolution gridded probabilistic precipitation and temperature time series for the hawaiian islands. J. Hydrometeorol. 2019, 20, 509-529. [CrossRef]

18. Beguería, S.; Vicente-Serrano, S.M. SPEI: Calculation of the Standardised Precipitation-Evapotranspiration Index. R package Version 1.7. 2017. Available online: https:/CRAN.R-project.org/package=SPEI (accessed on 16 September 2017).

19. R Core Team. R: A Language and Environment for Statistical Computing; R Foundation for Statistical Computing: Vienna, Austria, 2019. Available online: https://www.R-project.org/ (accessed on 16 September 2017).

20. Guttman, N. Accepting the standardized precipitation index: A calculation algorithm. J. Am. Water Resour. Assoc. 1999, 35, 311-322. [CrossRef]

21. Willmott, C.J. Some comments on the evaluation of model performance. Bull. Am. Meteorol. Soc. 1982, 63, 1309-1313. [CrossRef]

22. Cumbie-Ward, R.V.; Boyles, R.P. Evaluation of a high-resolution SPI for monitoring local drought severity. J. Appl. Meteorol. Climatol. 2016, 55, 2247-2262. [CrossRef]

23. Hao, Z.; AghaKouchak, A. A nonparametric multivariate multi-index drought monitoring framework. J. Hydrometeor. 2014, 15, 89-101. [CrossRef] 
24. Anderson, M.C.; Hain, C.; Otkin, J.; Zhan, X.; Mo, K.; Svoboda, M.; Wardlow, B.; Pimstein, A. An intercomparison of drought indicators based on thermal remote sensing and NLDAS-2 simulations with US Drought Monitor classifications. J. Hydrometeor. 2013, 14, 1035-1056. [CrossRef]

Publisher's Note: MDPI stays neutral with regard to jurisdictional claims in published maps and institutional affiliations.

(C) 2020 by the authors. Licensee MDPI, Basel, Switzerland. This article is an open access article distributed under the terms and conditions of the Creative Commons Attribution (CC BY) license (http://creativecommons.org/licenses/by/4.0/). 